\title{
Research on the current situation and countermeasures of experimental teaching management in the independent college
}

\author{
Lan Chen ${ }^{1, a}$,Jinglun Yang ${ }^{2, b}$ \\ ${ }^{1}$ Laboratory and assets management office,Zhuhai College of Jilin University, Zhuhai 519041,China \\ ${ }^{2}$ Sports education center,Zhuhai College of Jilin University,Zhuhai 519041, China

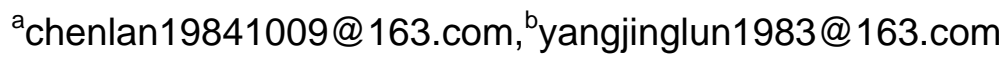

Keywords: independent college, experimental teaching, management.

\begin{abstract}
The current situation of experimental teaching management in the domestic independent colleges is expounded in this paper. The major problems of experimental teaching management are stated from the following four aspects: teaching staff management, open laboratory management, experimental resource management and information-based experimental teaching. With regard to the sustainable development of the independent colleges, the college leadership shall transform the concept, focus on the experimental teaching, formulate the incentive policies on the personnel management, strengthen the construction of regulatory system, increase the capital investment, actively promote the open management and information management of the college laboratory and make great efforts to solve the existing management problems of the experimental teaching education in the independent colleges.
\end{abstract}

\section{Introduction}

The independent college is the carrier of carrying out the new educational mechanism, cultivating the applied talents and improving the student's practical ability and innovative consciousness. Over the past decade, there are more than 300 independent colleges all over the country. At the same time, the experimental teaching is a key part of cultivating the applied talents. The experimental teaching plays an important role in the improvement of the student's comprehensive quality and practical ability in the era of knowledge-driven economy. With the fast development of independent colleges, there are some constraints, especially the experimental teaching management. The experimental teaching management is directly related with the healthy development of the independent colleges.

\section{Existing problems of experimental teaching management}

2.1 The construction and management of experimental teaching staff. The teaching staff is a key component to guarantee the successful implementation of experimental teaching ${ }^{[1]}$. Therefore, the construction of teaching staff plays an important role in the experimental teaching management, experimental technology development and innovative talent cultivation. The conventional theoretical teaching concepts have exerted an great influence in the construction of the experimental teaching staff. The major problems include: (1)inaccurate comprehensive positioning: at a long term, the experimental teaching staff is considered as "instructional assistant". Thus the gap between the construction of experimental teaching staff and higher education development is gradually widening, which it has affected the improvement of experimental teaching education; (2) the cultivation of experimental teaching staff can't keep up with the higher education development: the independent colleges generally pay more attention to the construction of theoretical teaching staff rather than the construction of experimental teaching staff; in general, the independent colleges focus on the organization of teaching staff rather than the cultivation of teaching staff. Under such conditions, the experimental staff are much difficult to improve their basic professional competence and technology level so as to meet the development requirements of experimental technology. As a consequence, the talent cultivation quality is also influenced. 
2.2 Open laboratory management. The open laboratory management is the important channel to deepen the reform of the experimental teaching in the independent colleges, improve the effectiveness of experimental teaching, give the students the chance to achieve the self-directed development and do the practical exercises, arouse the student's innovation ideas and consciousness, and take a comprehensive training on the student's scientific attitudes, innovative thinking, entrepreneurial ability and practicable ability ${ }^{[2-3]}$. However, the majority of independent college laboratories currently are just open to the specialized students. The open laboratory management is involved with the following problems: (1) low participation degree: The student source of the independent colleges are essentially different from the student source of the general universities. In particular, the majority of the independent colleges adopt the credit system. Under such circumstances, the students are able to finish school as long as the students get the scheduled credits. In this way, the students are not touched by the open laboratory that is unable to get the credits. (2) lack of the corresponding management system and financial support: the management system and financial support can guarantee the smooth development of the experimental teaching. However, the independent colleges are void of the complete management system and incentive system as well as subsequent financial support. Consequently, it is much difficult to promote the progress of open laboratory management.

2.3 Development and management of experimental teaching resources. Over the past decade, quite a few of independent colleges have over ten thousand of the students. For most of independent colleges, they have the specified scale of running the school, stable settings of the disciplines and large-scale laboratory. At the initial stage of running the school, many independent colleges are eager to meet the demands of the experimental teaching so that the courses can be smoothly started. As a result, the independent colleges may not think over the overall planning including the construction of the disciplines, specialty and enrollment size. The laboratory is just established based on the requirements of the given specialty and courses. Therefore, the construction of the laboratory is short of the long-term planning and overall considerations. For instance, the repeated laboratory construction projects based on the similar specialties, repeated purchase of experimental facilities, low resource utilization, limited experimental facilities, excessive utilization of some facilities, short service life, etc. All these factors have influenced the normal operation of the college laboratory. On one side, the repeated laboratory construction gives rise to the excessive waste of experimental teaching resources; on the other side, the decentralized approach of laboratory construction, application and management will bring about the unreasonable experimental resource allocation or deficiency of the experimental facilities ${ }^{[4]}$.

2.4 Outdated information management of experimental teaching. In the modern times, the advanced information management of the experimental teaching is still not implemented in the independent colleges. Most of the laboratory management tasks are manually conducted of which its management efficiency is quite low. To begin with, with the expansion of the college enrollment size, the experimental teaching resources are also increased, especially the public experimental teaching resources in the faculties. As a result of the outdated management methods, the experimental resources can not be fully utilized in causing the resource waste. At the same time, the outdated management method has further hindered the effective sharing and utilization of the experimental resources in the independent colleges ${ }^{[5]}$. Next, the independent colleges are generally short of the scalable information management system. Therefore, it is much difficult to achieve the centralized management,decentralized operation and information sharing of the experimental teaching resources. At present, the organization and management efficiency of the experimental teaching is not essentially improved in the independent colleges. Finally, the outdated management method is not beneficial to achieve the progress of the open laboratory management. With regard to the insufficient information management system, the laboratory administrators are unable to properly solve the student's problems. 


\section{Improve the experimental teaching management ability and talent cultivation quality}

\subsection{Strengthen the construction of experimental teaching staff and improve the experimental} teaching level. The experimental teaching staff is an important manifestation of human resources, which it is directly involved into the daily experimental teaching activities and talent cultivation. In other words, the experimental teaching quality and talent cultivation quality are closely correlated with the overall quality of experimental teaching staff ${ }^{[6-7]}$.The independent college leadership and personnel management department shall transform the old concepts, start from the cultivation of applied talents, focus on the experimental teaching and the construction of experimental teaching staff. According to the instructional tasks, these teaching staff shall be called as "laboratory teachers"; that is to say that the independent colleges shall abandon the practices of considering the experimental teaching staff as "instructional assistant". In addition, the college leadership shall also introduce some incentive policies on the development of experimental teaching staff. For instance, professional title assessment, wages and benefits, assessment measures, subsequent talent cultivation, etc. All these measures are designed to promote the continuous development of experimental teaching staff and arouse their innovative spirit and working enthusiasm.

3.2 Actively promote the open laboratory management and improve the student's learning initiative. The open laboratory management is an important mode of cultivating the innovative talents during the experimental teaching process. In the independent colleges, the implementation of open laboratory management can not only strengthen the student's theory knowledge and broaden the student's vision, but also improve the student's learning initiatives ${ }^{[8]}$. During the process, some problems shall be further solved. Above all, the independent college leadership shall make a reform on the evaluation methods of the student's performance, focus on the examination of the student's practical ability, take some rewarding measures and arouse the student's enthusiasm in the experimental teaching; next, it is necessary to set up the special funds on the experimental teaching, pay the cost of material consumption and additional personnel expenses, etc. Finally, the standardization of daily open laboratory management can ensure the systematical management of the college laboratory and exerts a greater influence in the improvement of the student's learning initiatives.

3.3 Strengthen the optimization and integration of experimental teaching resources. In order to strengthen the reasonable management of experimental teaching resources, it is feasible for the specific college departments to integrate the public resources in the faculties and achieve the unified management. Through the "centralized management and resources sharing”, it is possible to achieve the optimization and integration of the experimental teaching resources. For instance: (1) the public teaching resources shall be uniformly constructed, managed and shared; (2) it is necessary to achieve the centralized and classified management on the construction of the professional laboratories according to the requirements of similar disciplines or courses.

With the development of modern technology, the correlation across the disciplines is becoming closer and closer; meanwhile, the disadvantages of the decentralized management mode have been increasingly highlighted. In fact, the experimental resource sharing is a kind of technological issues and a kind of cognitive and management problems. On one hand, the independent college leadership shall truly recognize the essence and importance of optimized resource allocation and have a correct understanding on the resource sharing. On the other hand, it needs to make a scientific definition on the border of experimental resource sharing; the shared resources shall not be mixed with the some specialized experimental teaching resources. It is designed to prevent the low efficiency of specialized experimental teaching resources ${ }^{[9]}$.

3.4 Explore the information-based management of experimental teaching in the independent colleges. During the information-based management, it is necessary to apply the computer networking technology, make the comprehensive information management through the scientific management concepts and advanced database technology and deal with the complicated experimental teaching problems. The information-based management is designed to cultivate the talents in a scientific, standardized and convenient way. For the past few years, the colleges have 
unceasingly deepened the reform of experimental teaching education; meanwhile, the information-based management has gradually been recognized by the higher institutions. The independent colleges shall comply with the reform trends, actively explore the information-based management and develop the qualified management system and platform. For instance, the "laboratory management system" is applicable to manage the experimental teaching resources, prevent the repeated purchase of experimental facilities, reduce the waste of teaching resources and improve the usage rate of the experimental resources; the "open laboratory booking system" is accessible to make the online booking of the laboratory and meet the student's demands of utilizing the laboratory out of class so as to improve the service level and make a further progress on the open laboratory management; the "experimental teaching management system" is available to arrange the experimental curriculum, conduct the special experiments, receive the student's feedback on the experimental teaching and evaluation on the teachers. In this way, it is possible to promote the further progress of the teachers and laboratory technicians and improve the experimental teaching quality.

\section{Summary}

The experimental teaching is an actual step to strengthen the student's analysis ability, problem-solving ability, practical ability and innovative spirit. The experimental teaching management is beneficial to improve the student's comprehensive ability, teamwork spirit and creative thinking. However, it is impossible to completely transform the outdated experimental teaching management overnight. All of the college departments shall make joint efforts to solve the existing problems. Therefore, the college leadership shall transform the educational ideology, change the education concepts, take a lead to make a thoughtful thinking, find out the efficient solutions and make great efforts to overcome the difficulties of the experimental teaching management.

\section{References}

[1] $\mathrm{Hu}$ Jinhong, Explore the separation of experimental teaching staff from the positioning of “instructional assistant”, Experimental Technology and Management,2013,01:5-7.

[2]Yang Wei, Open laboratory management, Experimental Technology and Management,2012,01:186-187+194.

[3] Peng Ruwu, Xu Haihua, Practice and exploration of open laboratory management in the colleges, Laboratory Science,2013,01:129-132.

[4] Liu Yasong,Wei Jingguang, Analyze the existing problems and countermeasures of practical teaching in the independent colleges, Research and Exploration in Laboratory,2013,06:368-370+393.

[5] Chen Shuangshuang, Preliminary exploration of information management of the experimental teaching resources, Science and Technology Innovation Herald,2013,13:191-192.

[6] Qian Xiaoming, Explore the construction of the college's experimental teaching staff in the new era, Experimental Technology and Management,2013,01:203-205.

[7] Qian Xiaoming, Study the performance assessment methods for the college's experimental teaching staff in the new era, Research and Exploration in Laboratory,2014,04:133-136.

[8] Rong Huawei, Qian Xiaoming, Qian Jingzhu, Exploration and practices of the open laboratory management in the college, Experimental Technology and Management,2014,12:233-236.

[9] Tian Hong, Analyze the existing problems and countermeasures of the experimental teaching in 
the colleges, Experiment Science and Technology,2014,01:91-93. 